\title{
Existence of Solution for Impulsive Differential Equations with Nonlinear Derivative Dependence via Variational Methods
}

\author{
Lizhao Yan, ${ }^{1,2}$ Jian Liu, $^{3}$ and Zhiguo Luo ${ }^{2}$ \\ ${ }^{1}$ Department of Mathematics, Hunan Normal University, Changsha, Hunan 410081, China \\ ${ }^{2}$ Hunan Normal University Press, Changsha, Hunan 410081, China \\ ${ }^{3}$ School of Economics and Management, Changsha University of Science and Technology, Changsha, Hunan 410004, China
}

Correspondence should be addressed to Zhiguo Luo; luozg@hunnu.edu.cn

Received 30 May 2013; Revised 1 August 2013; Accepted 22 August 2013

Academic Editor: M. Victoria Otero-Espinar

Copyright (C) 2013 Lizhao Yan et al. This is an open access article distributed under the Creative Commons Attribution License, which permits unrestricted use, distribution, and reproduction in any medium, provided the original work is properly cited.

We use variational methods and iterative methods to investigate the solutions of impulsive differential equations with nonlinear derivative dependence. The conditions for the existence of solutions are established. The main results are also demonstrated with examples.

\section{Introduction}

Many dynamical systems have an impulsive dynamical behavior due to abrupt changes at certain instants during the evolution process. The mathematical description of these phenomena leads to impulsive differential equations. Recent development in this field has been motivated by many applied problems, such as control theory, population dynamics, and medicine [1-9].

We consider the following nonlinear Dirichlet boundary value problems for impulsive differential equations:

$$
\begin{gathered}
-\left(\left|u^{\prime}(t)\right|^{p-2} u^{\prime}(t)\right)^{\prime}+g(t)|u(t)|^{p-2} u(t) \\
=f\left(t, u(t), u^{\prime}(t)\right), \quad t \neq t_{j}, \text { a.e. } t \in[0, T], \\
\Delta u^{\prime}\left(t_{j}\right)=\left|u^{\prime}\left(t_{j}^{+}\right)\right|^{p-2} u^{\prime}\left(t_{j}^{+}\right)-\left|u^{\prime}\left(t_{j}^{-}\right)\right|^{p-2} u^{\prime}\left(t_{j}^{-}\right) \\
=I_{j}\left(u\left(t_{j}\right)\right), \quad j=1,2, \ldots, l, \\
u(0)=u(T)=0,
\end{gathered}
$$

where $p \geq 2,0=t_{0}<t_{1}<t_{2}<\cdots<t_{l}<t_{l+1}=T$, $g \in L^{\infty}[0, T], f:[0, T] \times R \times R \rightarrow R$ is continuous, and $I_{j}: R \rightarrow R, j=1,2, \ldots, l$, are continuous.
The characteristic of (1) is the presence of the first order derivative in the nonlinearity term. Most of the results concerning the existence of solutions of these equations are obtained using upper and lower solutions methods, coincidence degree theory, and fixed point theorems [10-14]. However, to the best of our knowledge, there are few papers concerned with the existence of solutions for impulsive boundary value problems like problem (1) by using variational methods. Motivated by $[15,16]$, in this paper we will fill the gap in this area.

When there is no derivative in the nonlinearity term, problem (1) has been extensively studied by [17-23], using variational methods. We know, contrary to these equations, (1) is not variational and the well-developed critical point theory is of no avail for, at least, a direct attack to problem (1). The technique used in this paper consists of, associating with problem (1), a family of the following Dirichlet boundary value problems with no dependence on the derivative of the solution. Namely, for each $w \in W_{0}^{1, p}$, we consider the problem

$$
\begin{aligned}
- & \left(\left|u^{\prime}(t)\right|^{p-2} u^{\prime}(t)\right)^{\prime}+g(t)|u(t)|^{p-2} u(t) \\
& =f\left(t, u(t), w^{\prime}(t)\right), \quad t \neq t_{j}, \text { a.e. } t \in[0, T],
\end{aligned}
$$




$$
\begin{gathered}
\Delta u^{\prime}\left(t_{j}\right)=\left|u^{\prime}\left(t_{j}^{+}\right)\right|^{p-2} u^{\prime}\left(t_{j}^{+}\right)-\left|u^{\prime}\left(t_{j}^{-}\right)\right|^{p-2} u^{\prime}\left(t_{j}^{-}\right) \\
=I_{j}\left(u\left(t_{j}\right)\right), \quad j=1,2, \ldots, l, \\
u(0)=u(T)=0 .
\end{gathered}
$$

Now problem (2) is variational and we can treat it by variational methods.

In this paper, we need the following conditions.

$\left(f_{1}\right) f:[0, T] \times R \times R \rightarrow R$ is measurable in $t \in[0, T]$ for every $(x, \zeta) \in R \times R$ and continuous in $(x, \zeta) \in R \times R$ for a.e. $t \in[0, T]$.

$\left(f_{2}\right) f(t, x, \zeta)=o\left(|x|^{p-1}\right)$ as $x \rightarrow 0$ uniformly for $t \epsilon$ $[0, T]$ and $\zeta \in R$ and $f(t, x, 0) \neq 0$ for $t \in[0, T]$ and $x \in R$.

$\left(f_{3}\right)$ There exist constants $C>0$ and $r \in(p,+\infty)$ such that $|f(t, x, \zeta)| \leq C\left(1+|x|^{r-1}\right), \quad \forall t \in[0, T], x \in R, \zeta \in R$.

$\left(f_{4}\right)$ There exist constants $\mu>p$ and $x_{0}>0$ such that

$$
\begin{aligned}
& 0<\mu F(t, x, \zeta) \leq x f(t, x, \zeta), \\
& \forall t \in[0, T],|x| \geq x_{0}, \zeta \in R,
\end{aligned}
$$

where $F(t, x, \zeta)=\int_{0}^{x} f(t, s, \zeta) d s$.

$\left(f_{5}\right)$ There exist constants $a, b>0$ such that

$F(t, x, \zeta) \geq a|x|^{\mu}-b, \quad \forall t \in[0, T], x \in R, \zeta \in R$.

$\left(f_{6}\right)$ The function $f$ satisfies the following conditions:

$$
\begin{gathered}
\left|f(t, x, \zeta)-f\left(t, x^{\prime}, \zeta\right)\right| \leq L_{1}\left|x-x^{\prime}\right|^{p-1}, \\
\forall t \in[0, T], x, x^{\prime} \in\left[-\rho_{1}, \rho_{1}\right], \zeta \in R \\
\left|f(t, x, \zeta)-f\left(t, x, \zeta^{\prime}\right)\right| \leq L_{2}\left|\zeta-\zeta^{\prime}\right|^{p-1}, \\
\forall t \in[0, T], x \in\left[-\rho_{1}, \rho_{1}\right], \zeta, \zeta^{\prime} \in R,
\end{gathered}
$$

where $\rho_{1}$ is a constant.

$\left(I_{1}\right) I_{j}(j=1,2, \ldots, l)$ are odd and nondecreasing, and there exist constants $a_{j}>0, b_{j}>0$, and $r_{j} \in[0, p-$ 1), $j=1,2, \ldots, l$ such that

$$
\left|I_{j}(u)\right| \leq a_{j}+b_{j}|u|^{r_{j}}, \quad \text { for } j=1,2, \ldots, l .
$$

$\left(I_{2}\right)$ There exists $0<\theta \leq p$ such that

$$
\theta \int_{0}^{u} I_{j}(s) d s \geq u I_{j}(u)>0, \quad \forall u>0 .
$$

$\left(I_{3}\right)\left|I_{j}(u)-I_{j}(v)\right| \leq \alpha_{j}|u-v|^{p-1}$, for all $u, v \in\left[-\rho_{1}, \rho_{1}\right]$, $j=1,2, \ldots, l$.

The paper is organized as follows: Section 2 is the preliminaries of this paper, Section 3 is devoted to show the solvability of problem (2), and Section 4 will show the solvability of problem (1).

\section{Preliminaries}

Firstly, we recall some facts which will be used in the proof of our main result. It has been shown, for instance, in [16] that the set of all eigenvalues of the following problem

$$
\begin{gathered}
\left(\left|u^{\prime}(t)\right|^{p-2} u^{\prime}(t)\right)^{\prime}+\lambda|u(t)|^{p-2} u(t)=0, \quad t \in[0, T], \\
u(0)=u(T)=0
\end{gathered}
$$

is given by the sequence of positive numbers

$$
\lambda_{k}=(p-1)\left(\frac{k \pi_{p}}{T}\right)^{p}, \quad k=1,2, \ldots
$$

where

$$
\pi_{p}=2 \int_{0}^{1} \frac{d s}{\left(1-s^{p}\right)^{1 / p}}=\frac{2 \pi}{p \sin (\pi / p)} .
$$

Each eigenvalue $\lambda_{k}$ is simple with the associated eigenfunction

$$
\varphi_{k}(x)=\sin _{p}\left(\frac{k \pi_{p} x}{T}\right), \quad \text { for } 0 \leq x \leq T .
$$

We recall the well-known characterization of $\lambda_{1}$ as the best constant in the Poincaré inequality

$$
\int_{0}^{T}\left|u^{\prime}(t)\right|^{p} d t \geq \lambda_{1} \int_{0}^{T}|u(t)|^{p} d t, \quad \forall u \in W_{0}^{1, p}(0, T) .
$$

Let $W_{0}^{1, p}(0, T)$ be the Sobolev space endowed with the norm

$$
\|u\|=\left(\int_{0}^{T}\left|u^{\prime}(t)\right|^{p} d t+\int_{0}^{T} g(t)|u(t)|^{p} d t\right)^{1 / p} .
$$

Throughout the paper, it will be assumed that ess inf $_{t \in[0, T]} g(t)=m>-\lambda_{1}$. We also consider the norm

$$
\begin{gathered}
\|u\|_{W_{0}^{1, p}}=\left(\int_{0}^{T}\left|u^{\prime}(t)\right|^{p} d t\right)^{1 / p}, \\
\|u\|_{p}=\left(\int_{0}^{T}|u(t)|^{p} d t\right)^{1 / p} .
\end{gathered}
$$

We need the following Lemmas.

Lemma 1 (see [24, Lemma 2.4]). If $\operatorname{ess~inf}_{t \in[0, T]} g(t)=m>$ $-\lambda_{1}$, then the norms $\|\cdot\|$ and $\|\cdot\|_{W_{0}^{1, p}}$ are equivalent.

Lemma 2 (see [24, Lemma 2.5]). There exists $C_{2}>0$ such that if $u \in W_{0}^{1, p}$, then

$$
\begin{gathered}
\|u\|_{\infty} \leq\left(\frac{T}{q+1}\right)^{1 / q}\left(\int_{0}^{T}\left|u^{\prime}(s)\right|^{p} d s\right)^{1 / p}, \\
\|u\|_{\infty} \leq C_{2}\|u\| .
\end{gathered}
$$


Lemma 3 (see [24, Lemma 2.6]). Let $u \in W_{0}^{1, p}(0, T)$; then there exists $C_{1} \in(0,1)$ such that

$$
\|u\|_{p} \leq \frac{1}{\sqrt[p]{\lambda_{1} C_{1}}}\|u\| .
$$

For $u \in W^{1, p}(0, T)$, we have that $u$ and $u^{\prime}$ are both absolutely continuous. Hence $\Delta u^{\prime}(t)=u^{\prime}\left(t^{+}\right)-u^{\prime}\left(t^{-}\right)=0$ for any $t \in[0, T]$. If $u \in W_{0}^{1, p}(0, T)$, then $u$ is absolutely continuous. In this case, $\Delta u^{\prime}(t)=u^{\prime}\left(t^{+}\right)-u^{\prime}\left(t^{-}\right)=0$ may not hold for some $t \in[0, T]$. It leads to the impulsive effects. As a consequence, we need to introduce a different concept of solution.

Definition 4. A function

$$
\begin{aligned}
& u \in\left\{u \in W_{0}^{1, p}(0, T):\right. \\
& \left.\quad\left|u^{\prime}\right|^{p-2} u^{\prime} \in W^{1, \infty}(0, T) \backslash\left\{t_{1}, t_{2}, \ldots, t_{l}\right\}\right\}
\end{aligned}
$$

is said to be a classical solution of problem (1) if $u$ satisfies the equation a.e. on $[0, T] \backslash\left\{t_{1}, t_{2}, \ldots, t_{l}\right\}$ and the limits $u^{\prime}\left(t_{j}^{+}\right)$, $u^{\prime}\left(t_{j}^{-}\right)$and $j=1,2, \ldots, l$, exist and satisfy the impulsive condition

$$
\begin{aligned}
\Delta u^{\prime}\left(t_{j}\right)= & \left|u^{\prime}\left(t_{j}^{+}\right)\right|^{p-2} u^{\prime}\left(t_{j}^{+}\right) \\
& -\left|u^{\prime}\left(t_{j}^{-}\right)\right|^{p-2} u^{\prime}\left(t_{j}^{-}\right)=I_{j}\left(u\left(t_{j}\right)\right)
\end{aligned}
$$

and the boundary condition $u(0)=u(T)=0$.

We have the following fact. Take $v \in W_{0}^{1, p}(0, T)$ and multiply the equation in problem (1) by $v$ and integrate from 0 to $T$ :

$$
\begin{gathered}
-\int_{0}^{T}\left(\left|u^{\prime}(t)\right|^{p-2} u^{\prime}(t)\right)^{\prime} v(t) d t \\
+\int_{0}^{T} g(t)|u(t)|^{p-2} u(t) v(t) d t \\
=\int_{0}^{T} f\left(t, u(t), u^{\prime}(t)\right) v(t) d t .
\end{gathered}
$$

The first term is now

$$
\begin{gathered}
-\int_{0}^{T}\left(\left|u^{\prime}(t)\right|^{p-2} u^{\prime}(t)\right)^{\prime} v(t) d t \\
=-\sum_{j=0}^{l} \int_{t_{j}}^{t_{j+1}}\left(\left|u^{\prime}(t)\right|^{p-2} u^{\prime}(t)\right)^{\prime} v(t) d t, \\
\int_{t_{j}}^{t_{j+1}}\left(\left|u^{\prime}(t)\right|^{p-2} u^{\prime}(t)\right)^{\prime} v(t) d t \\
=\left|u^{\prime}\left(t_{j+1}^{-}\right)\right|^{p-2} u^{\prime}\left(t_{j+1}^{-}\right) v\left(t_{j+1}\right) \\
-\left|u^{\prime}\left(t_{j}^{+}\right)\right|^{p-2} u^{\prime}\left(t_{j}^{+}\right) v\left(t_{j}\right) \\
-\int_{t_{j}}^{t_{j+1}}\left|u^{\prime}(t)\right|^{p-2} u^{\prime}(t) v^{\prime}(t) d t .
\end{gathered}
$$

Hence

$$
\begin{aligned}
& -\int_{0}^{T}\left(\left|u^{\prime}(t)\right|^{p-2} u^{\prime}(t)\right)^{\prime} v(t) d t \\
& =\sum_{j=1}^{l} \Delta u^{\prime}\left(t_{j}\right) v\left(t_{j}\right)-\left|u^{\prime}(T)\right|^{p-2} u^{\prime}(T) v(T) \\
& \quad+\left|u^{\prime}(0)\right|^{p-2} u^{\prime}(0) v(0)+\int_{0}^{T}\left|u^{\prime}(t)\right|^{p-2} u^{\prime}(t) v^{\prime}(t) d t \\
& =\sum_{j=1}^{l} I_{j}\left(u\left(t_{j}\right)\right) v\left(t_{j}\right)+\int_{0}^{T}\left|u^{\prime}(t)\right|^{p-2} u^{\prime}(t) v^{\prime}(t) d t .
\end{aligned}
$$

Definition 5. We say that a function $u \in W_{0}^{1, p}(0, T)$ is a weak solution of problem (1) if the identity

$$
\begin{aligned}
& \int_{0}^{T}\left|u^{\prime}(t)\right|^{p-2} u^{\prime}(t) v^{\prime}(t) d t+\int_{0}^{T} g(t)|u(t)|^{p-2} u(t) v(t) d t \\
& +\sum_{j=1}^{l} I_{j}\left(u\left(t_{j}\right)\right) v\left(t_{j}\right)=\int_{0}^{T} f\left(t, u(t), u^{\prime}(t)\right) v(t) d t
\end{aligned}
$$

holds for any $v \in W_{0}^{1, p}(0, T)$.

Proposition 6. Under the hypotheses $\left(f_{1}\right)$ and $\left(f_{2}\right)$, the functional $\varphi_{w}: W_{0}^{1, p}(0, T) \rightarrow R$ defined by

$$
\begin{aligned}
\varphi_{w}(u)= & \frac{1}{p}\|u\|^{p}-\int_{0}^{T} F\left(t, u(t), w^{\prime}(t)\right) d t \\
& +\sum_{j=1}^{l} \int_{0}^{u\left(t_{j}\right)} I_{j}(s) d s
\end{aligned}
$$

is continuous and differentiable and

$$
\begin{aligned}
\varphi_{w}^{\prime}(u) v= & \int_{0}^{T}\left|u^{\prime}(t)\right|^{p-2} u^{\prime}(t) v^{\prime}(t) d t \\
& +\int_{0}^{T} g(t)|u(t)|^{p-2} u(t) v(t) d t \\
& +\sum_{j=1}^{l} I_{j}\left(u\left(t_{j}\right)\right) v\left(t_{j}\right) \\
& -\int_{0}^{T} f\left(t, u(t), w^{\prime}(t)\right) v(t) d t
\end{aligned}
$$

for any $v \in W_{0}^{1, p}(0, T)$. Moreover, the critical point of $\varphi_{w}$ is a classical solutions of problem (2). 
Proof. Using the assumptions $\left(f_{1}\right)$, we can obtain the continuity and differentiability of $\varphi_{w}$ and that $\varphi_{w}^{\prime}: W_{0}^{1, p}(0, T) \rightarrow$ $\left(W_{0}^{1, p}(0, T)\right)^{*}$ is defined by

$$
\begin{aligned}
\varphi_{w}^{\prime}(u) v= & \int_{0}^{T}\left|u^{\prime}(t)\right|^{p-2} u^{\prime}(t) v^{\prime}(t) d t \\
& +\int_{0}^{T} g(t)|u(t)|^{p-2} u(t) v(t) d t \\
& +\sum_{j=1}^{l} I_{j}\left(u\left(t_{j}\right)\right) v\left(t_{j}\right) \\
& -\int_{0}^{T} f\left(t, u(t), w^{\prime}(t)\right) v(t) d t
\end{aligned}
$$

for any $v \in W_{0}^{1, p}(0, T)$. It follows that the critical point of $\varphi_{w}$ is the weak solution of (2). Moreover, it is a classical solution of problem (2).

Evidently, $u(0)=u(T)=0$ since $u \in W_{0}^{1, p}(0, T)$. By the definition of weak solution, we have

$$
\begin{aligned}
& \int_{0}^{T}\left|u^{\prime}(t)\right|^{p-2} u^{\prime}(t) v^{\prime}(t) d t+\int_{0}^{T} g(t)|u(t)|^{p-2} u(t) v(t) d t \\
& +\sum_{j=1}^{l} I_{j}\left(u\left(t_{j}\right)\right) v\left(t_{j}\right)-\int_{0}^{T} f\left(t, u(t), w^{\prime}(t)\right) v(t) d t=0 .
\end{aligned}
$$

Choose $v \in W_{0}^{1, p}(0, T)$ with $v(t)=0$ for every $t \in\left[0, t_{j}\right] \cup$ $\left[t_{j+1}, T\right]$; then

$$
\begin{aligned}
& \int_{t_{j}}^{t_{j+1}}\left|u^{\prime}(t)\right|^{p-2} u^{\prime}(t) v^{\prime}(t) d t \\
& +\int_{t_{j}}^{t_{j+1}} g(t)|u(t)|^{p-2} u(t) v(t) d t \\
& \quad=\int_{t_{j}}^{t_{j+1}} f\left(t, u(t), w^{\prime}(t)\right) v(t) d t .
\end{aligned}
$$

This implies that

$$
\begin{aligned}
& -\left(\left|u^{\prime}(t)\right|^{p-2} u^{\prime}(t)\right)^{\prime}+g(t)|u(t)|^{p-2} u(t) \\
& =f\left(t, u(t), w^{\prime}(t)\right), \quad \text { a.e. } t \in\left(t_{j}, t_{j+1}\right) .
\end{aligned}
$$

Hence, $|u|^{p-2} u^{\prime} \in W^{1, \infty}\left(t_{j}, t_{j+1}\right)$ for every $j=1,2, \ldots, l$. The impulsive condition in (2) is satisfied. This completes the proof.

We will obtain the critical points of $\varphi_{w}$ by using the Mountain Pass Theorem. Therefore, we state this theorem precisely.
Lemma 7 (see [25]). Let $X$ be a real Banach space and $I \epsilon$ $C^{\prime}(X, R)$ satisfy (PS)-condition. Suppose that I satisfies the following conditions:

(i) $I(0)=0$;

(ii) there exists constants $\rho, \alpha>0$ such that $\left.I\right|_{\partial B_{\rho}(0)} \geq \alpha$;

(iii) there exists $e \in X \backslash \bar{B}_{\rho}(0)$ such that $I(e) \leq 0$.

Then I possesses a critical value $c \geq \alpha$ given by

$$
c=\inf _{g \in \Gamma} \max _{s \in[0,1]} I(g(s)),
$$

where $B_{\rho}(0)$ is an open ball in $X$ of radius $\rho$ centered at 0 and

$$
\Gamma=\{g \in C([0,1], X): g(0)=0, g(1)=e\} .
$$

\section{The Solvability of (2)}

Theorem 8. Suppose that $\left(f_{1}\right)-\left(f_{5}\right)$ and $\left(I_{1}\right)$ hold; then there exist positive constants $d_{1}$ and $d_{2}$ such that, for each $w \in$ $W_{0}^{1, p}(0, T)$, problem (2) has one solution $u_{w}$ such that $d_{1} \leq$ $\left\|u_{w}\right\| \leq d_{2}$.

Proof. (I) We show that $\varphi_{w}$ satisfies the (PS)-condition.

Assume that $\left\{u_{n}\right\}_{n \in \mathbf{N}} \subset W_{0}^{1, p}(0, T)$ is a sequence such that $\left\{\varphi_{w}\left(u_{n}\right)\right\}_{n \in \mathbf{N}}$ is bounded and $\varphi_{w}^{\prime}\left(u_{n}\right) \rightarrow 0$ as $n \rightarrow+\infty$. We will prove that the sequence $\left\{u_{n}\right\}_{n \in \mathbf{N}}$ is bounded. Obviously, there exists a constant $C_{3}>0$ such that

$$
\left|\varphi_{w}\left(u_{n}\right)\right| \leq C_{3}, \quad\left|\varphi_{w}^{\prime}\left(u_{n}\right)\right| \leq C_{3} \quad \text { for } n \in \mathbf{N} .
$$

We set

$$
m_{0}=\max \left\{a_{1}, a_{2}, \ldots, a_{l}\right\}, \quad M_{0}=\max \left\{b_{1}, b_{2}, \ldots, b_{l}\right\} .
$$

From (17), (25), (26), and (33), $\left(f_{4}\right)$, and $\left(I_{1}\right)$, we have

$$
\begin{aligned}
\mu & \varphi_{w}\left(u_{n}\right)-\varphi_{w}^{\prime}\left(u_{n}\right) u_{n} \\
= & \left(\frac{\mu}{p}-1\right)\left\|u_{n}\right\|^{p}-\int_{0}^{T}\left(\mu F\left(t, u_{n}, w^{\prime}\right)-f\left(t, u_{n}, w^{\prime}\right) u_{n}\right) d t \\
& +\sum_{j=1}^{l}\left[\mu \int_{0}^{u_{n}\left(t_{j}\right)} I_{j}(s) d s-I_{j}\left(u_{n}\left(t_{j}\right)\right) u_{n}\left(t_{j}\right)\right] \\
\geq & \left(\frac{\mu}{p}-1\right)\left\|u_{n}\right\|^{p}-\sum_{j=1}^{l}\left[\left(a_{j}+b_{j}\left|u_{n}\left(t_{j}\right)\right|^{r_{j}}\right) u_{n}\left(t_{j}\right)\right] \\
& -\sum_{j=1}^{l}\left(a_{j}+b_{j}|s|^{r_{j}}\right) d s-C_{4} \\
\geq & \left(\frac{\mu}{p}-1\right)\left\|u_{n}\right\|^{p} \\
& -(\mu+1)\left(C_{2} l m_{0}\left\|u_{n}\right\|+M_{0} \sum_{j=1}^{l} C_{2}^{r_{j}+1}\left\|u_{n}\right\|^{r_{j}+1}\right)-C_{4} .
\end{aligned}
$$

By $p>r_{j}+1$, we obtain that $\left\{u_{n}\right\}$ is bounded in $W_{0}^{1, p}(0, T)$. 
Since $W_{0}^{1, p}(0, T)$ is a reflexive Banach space, passing to a subsequence if necessary, we can assume that

$$
\begin{gathered}
u_{n} \rightarrow u \quad \text { in } W_{0}^{1, p}(0, T), \\
u_{n} \longrightarrow u \quad \text { in } L^{p}(0, T), \\
u_{n} \longrightarrow u \quad \text { uniformly in } C[0, T] .
\end{gathered}
$$

Hence

$$
\begin{gathered}
\int_{0}^{T}\left(f\left(t, u_{n}, w^{\prime}\right)-f\left(t, u, w^{\prime}\right) u_{n}\right)\left(u_{n}(t)-u(t)\right) d t \rightarrow 0, \\
\sum_{j=1}^{l}\left[I_{j}\left(u_{n}\left(t_{j}\right)\right)-I_{j}\left(u\left(t_{j}\right)\right)\right]\left(u_{n}\left(t_{j}\right)-u\left(t_{j}\right)\right) \longrightarrow 0 .
\end{gathered}
$$

Notice that

$$
\begin{aligned}
& \left\langle\varphi_{w}^{\prime}\left(u_{n}\right)-\varphi_{w}^{\prime}(u), u_{n}-u\right\rangle \\
& =\int_{0}^{T}\left(\left|u_{n}^{\prime}(t)\right|^{p-2} u_{n}^{\prime}(t)-\left|u^{\prime}(t)\right|^{p-2} u^{\prime}(t)\right) \\
& \quad \times\left(u_{n}^{\prime}(t)-u^{\prime}(t)\right) d t \\
& \quad+\int_{0}^{T}\left(g(t)\left|u_{n}(t)\right|^{p-2} u_{n}(t)-|u(t)|^{p-2} u(t)\right) \\
& \quad \times\left(u_{n}(t)-u(t)\right) d t \\
& +\sum_{j=1}^{l}\left(I_{j}\left(u_{n}\left(t_{j}\right)\right)-I_{j}\left(u\left(t_{j}\right)\right)\left(u_{n}\left(t_{j}\right)-u\left(t_{j}\right)\right)\right) \\
& \quad+\int_{0}^{T}\left(f\left(t, u_{n}, w^{\prime}\right)-f\left(t, u, w^{\prime}\right)\right)\left(u_{n}(t)-u(t)\right) d t .
\end{aligned}
$$

From [26, Lemma 4.2], we see that there exists $C_{p}>0$, for any $x, y \in R$ :

$$
\left(|x|^{p-2} x-|y|^{p-2} y\right)(x-y) \geq C_{p}|x-y|^{p}, \quad p \geq 2 .
$$

Combining this inequality with (39), we have

$$
\begin{aligned}
& C_{p}\left(\int_{0}^{T}\left(\left|u_{n}^{\prime}(t)-u^{\prime}(t)\right|^{p}+g(t)\left|u_{n}(t)-u(t)\right|^{p}\right) d t\right) \\
& \leq\left\|\varphi_{w}^{\prime}\left(u_{n}\right)-\varphi_{w}^{\prime}(u)\right\|\left\|u_{n}-u\right\| \\
& \quad+\sum_{j=1}^{l}\left(I_{j}\left(u_{n}\left(t_{j}\right)\right)-I_{j}\left(u\left(t_{j}\right)\right)\left(u_{n}\left(t_{j}\right)-u\left(t_{j}\right)\right)\right) \\
& \quad+\int_{0}^{T}\left(f\left(t, u_{n}, w^{\prime}\right)-f\left(t, u, w^{\prime}\right)\right)\left(u_{n}(t)-u(t)\right) d t .
\end{aligned}
$$

It follows from (37)-(39) that $u_{n} \rightarrow u$ in $W_{0}^{1, p}(0, T)$. Hence, $\varphi_{w}$ satisfies (PS)-condition.

(II) We verify assumption (ii) of Lemma 7.
By $\left(f_{2}\right)$, there exists $\delta \in(0,1)$ such that

$$
|f(t, x, \zeta)| \leq \frac{\lambda_{1} C_{1}}{2}|x|^{p-1} \quad \text { for } t \in[0, T],|x| \leq \delta, \zeta \in R .
$$

Since $F(t, 0, \zeta)=0$, it follows that

$$
|F(t, x, \zeta)| \leq \frac{\lambda_{1} C_{1}}{2 p}|x|^{p} \quad \text { for } t \in[0, T],|x| \leq \delta, \zeta \in R .
$$

Using $\left(I_{1}\right)$, we have

$$
\sum_{j=1}^{l} \int_{0}^{u\left(t_{j}\right)} I_{j}(t) d t \geq 0
$$

Hence, from (18), (25), (35), $\left(f_{2}\right)$, and $\left(I_{1}\right)$, for $\|u\| \leq \delta / C_{2}$, we have

$$
\begin{aligned}
\varphi_{w}(u)= & \frac{1}{p}\|u\|^{p}-\int_{0}^{T} F\left(t, u(t), w^{\prime}(t)\right) d t \\
& +\sum_{j=1}^{l} \int_{0}^{u\left(t_{j}\right)} I_{j}(t) d t \\
\geq & \frac{1}{p}\|u\|^{p}-\frac{\lambda_{1} C_{1}}{2 p} \int_{0}^{T}|u(t)|^{p} d t \\
\geq & \frac{1}{p}\|u\|^{p}-\frac{1}{2 p}\|u\|^{p}=\frac{1}{2 p}\|u\|^{p} .
\end{aligned}
$$

Set $\alpha=(1 / 2 p)\left(\delta / C_{2}\right)^{p}, \rho=\delta / C_{2}$. Equation (45) shows that $\|u\|=\rho$ implies that $\varphi_{w}(u) \geq \alpha$; that is, $\varphi_{w}$ satisfies assumption (ii) of Lemma 7.

(III) We verify assumption (iii) of Lemma 7.

By $\left(I_{1}\right)$ and $\left(f_{5}\right)$, we know that for $s>1$

$$
\begin{aligned}
\varphi_{w}(s u)= & \frac{1}{p}\|s u\|^{p}-\int_{0}^{T} F\left(t, s u(t), w^{\prime}(t)\right) d t \\
& +\sum_{j=1}^{l} \int_{0}^{s u\left(t_{j}\right)} I_{j}(t) d t \\
\leq & \frac{1}{p}\|u\|^{p} s^{p}+l C_{2}\|u\| \sum_{j=1}^{l}\left(a_{j}+b_{j}|s|^{r_{j}}\right) C_{2}^{r_{j}}\|u\|^{r_{j}} \\
& -a|s|^{\mu} \int_{0}^{T}|u(t)|^{\mu} d t+b T .
\end{aligned}
$$

Take $v_{0} \in W_{0}^{1, p}(0, T)$ such that $\left\|v_{0}\right\|=1$. Since $\mu>p, a>0$, and $0 \leq r_{j}<p-1$, (46) implies that there exists $\xi_{1}>1$ such that $\|e\|>\rho$, and $\varphi_{w}(e)<0$ if we set $e=\xi_{1} v_{0}$. By Lemma 7 , $\varphi_{w}$ possesses a critical value $c^{\prime} \geq \alpha>0$ given by

$$
c^{\prime}=\inf _{g \in \Gamma \in[0,1]} \max _{s \in}(g(s)),
$$


where $\Gamma=\left\{g \in C\left([0,1], W_{0}^{1, p}(0, T)\right): g(0)=0, g(1)=e\right\}$. Obviously, $\varphi_{w}(0)=0$, so according to Lemma 7 , there exists $u_{w} \neq 0$ and $u_{w} \in X$, such that

$$
\varphi_{w}\left(u_{w}\right)=c^{\prime}, \quad \varphi_{w}\left(u_{w}\right)=0 .
$$

(IV) We prove that $d_{1} \leq\left\|u_{w}\right\| \leq d_{2}$.

Since $u_{w}$ is the solution of problem (2), we have

$$
\begin{aligned}
& \int_{0}^{T}\left|u_{w}^{\prime}\right|^{p} d t+\int_{0}^{T} g(t)\left|u_{w}\right|^{p} d t+\sum_{j=1}^{l} I_{j}\left(u_{w}\left(t_{j}\right)\right) u_{w}\left(t_{j}\right) \\
& \quad=\int_{0}^{T} f\left(t, u_{w}, w^{\prime}\right) u_{w} d t .
\end{aligned}
$$

So

$$
\left\|u_{w}\right\|^{p}+\sum_{j=1}^{l} I_{j}\left(u_{w}\left(t_{j}\right)\right) u_{w}\left(t_{j}\right)=\int_{0}^{T} f\left(t, u_{w}, w^{\prime}\right) u_{w} d t
$$

It follows from $\left(f_{2}\right)$ and $\left(f_{3}\right)$ that, given $\epsilon>0$, there exists a positive constant $C_{\epsilon}$, independent of $w$, such that

$$
|f(t, x, \zeta)| \leq \epsilon|x|^{p-1}+C_{\epsilon}|x|^{r-1} \text {. }
$$

Hence, using $\left(I_{1}\right)$, we have

$$
\begin{aligned}
\left\|u_{w}\right\|^{p} & \leq\left\|u_{w}\right\|^{p}+\sum_{j=1}^{l} I_{j}\left(u_{w}\left(t_{j}\right)\right) u_{w}\left(t_{j}\right) \\
& =\int_{0}^{T} f\left(t, u_{w}, w^{\prime}\right) u_{w} d t \\
& \leq \epsilon \int_{0}^{T}\left|u_{w}\right|^{p} d t+C_{\epsilon} \int_{0}^{T}\left|u_{w}\right|^{r} d t
\end{aligned}
$$

By Sobolev embedding theorem, we obtain

$$
\left\|u_{w}\right\|^{p} \leq \epsilon \cdot \frac{1}{\lambda_{1} C_{1}}\left\|u_{w}\right\|^{p}+C_{\epsilon} \cdot \frac{1}{\left(\lambda_{1} C_{1}\right)^{r / p}}\left\|u_{w}\right\|^{r} .
$$

Set $\epsilon / \lambda_{1} C_{1}=\epsilon^{\prime}$ and $C_{\epsilon} /\left(\lambda_{1} C_{1}\right)^{r / p}=C_{\epsilon}^{\prime}$; then

$$
\left(1-\epsilon^{\prime}\right)\left\|u_{w}\right\|^{p} \leq C_{\epsilon}^{\prime}\left\|u_{w}\right\|^{r}
$$

which implies

$$
\left\|u_{w}\right\| \geq d_{1} .
$$

From the inf max characterization of $u_{w}$ in (III), we obtain

$$
\varphi_{w}\left(u_{w}\right) \leq \max \varphi_{w}\left(s v_{0}\right)
$$

with $v_{0}$ chosen in (III). We estimate $\varphi_{w}\left(s v_{0}\right)$ using $\left(f_{5}\right)$ and $\left(I_{1}\right)$ :

$$
\begin{aligned}
\varphi_{w}\left(s v_{0}\right) \leq & \frac{1}{p} s^{p}-a|s|^{\mu} \int_{0}^{T}\left|v_{0}\right|^{\mu} d t+b T-a_{j} T \\
& -b_{j}|s|^{r_{j}} \int_{0}^{T}\left|v_{0}\right|^{r_{j}} d t=: h(s),
\end{aligned}
$$

whose maximum is achieved at some $s_{0}>0$ and the value $h\left(s_{0}\right)$ can be taken as $d_{2}$. Clearly it is independent of $w$. Which implies

$$
\left\|u_{w}\right\| \leq d_{2}
$$

This completes the proof.

Lemma 9. Suppose that $\left(f_{1}\right)-\left(f_{3}\right)$ hold and $\left(f_{4}\right),\left(f_{5}\right)$, and $\left(I_{1}\right)$ hold only for positive $x$; then there exist positive constants $d_{3}$, and $d_{4}$ such that, for each $w \in W_{0}^{1, p}(0, T)$, problem (2) has a positive solution $u_{w}$ such that $d_{3} \leq\left\|u_{w}\right\| \leq d_{4}$.

Proof. Set

$$
\begin{gathered}
\bar{f}(t, u, \zeta)= \begin{cases}f(t, u, \zeta), & \text { if } u \geq 0, \\
0, & \text { if } u<0,\end{cases} \\
\bar{I}_{j}(u)= \begin{cases}I_{j}(u), & \text { if } u \geq 0, \\
0, & \text { if } u<0 .\end{cases}
\end{gathered}
$$

Consider the function

$$
\begin{gathered}
-\left(\left|u^{\prime}(t)\right|^{p-2} u^{\prime}(t)\right)^{\prime}+g(t)|u(t)|^{p-2} u(t) \\
=\bar{f}\left(t, u(t), u^{\prime}(t)\right), \quad t \neq t_{j}, \quad \text { a.e. } t \in[0, T], \\
\Delta u^{\prime}\left(t_{j}\right)=\bar{I}_{j}\left(u\left(t_{j}\right)\right), \quad j=1,2, \ldots, l, \\
u(0)=u(T)=0 .
\end{gathered}
$$

Obviously, $\bar{f}$ satisfies $\left(f_{1}\right)-\left(f_{5}\right)$, and $\bar{I}_{j}$ satisfies $\left(I_{1}\right)$, so using Theorem 8, we obtained a solution $u_{w}$ of (60). Multiplying the equation by $u_{w}^{-}$and integrating by parks, we conclude that $u_{w}^{-} \equiv 0$. So $u_{w}$ is positive.

Theorem 10. Suppose that $\left(f_{1}\right)-\left(f_{5}\right)$ and $\left(I_{2}\right)$ hold; then there exist positive constants $d_{5}$ and $d_{6}$ such that, for each $w \in$ $W_{0}^{1, p}(0, T)$, problem (2) has one solution $u_{w}$ such that $d_{5} \leq$ $\left\|u_{w}\right\| \leq d_{6}$.

Proof. (I) We show that $\varphi_{w}$ satisfies the (PS)-condition.

Assume that $\left\{u_{n}\right\}_{n \in \mathbf{N}} \subset W_{0}^{1, p}(0, T)$ is a sequence such that $\left\{\varphi_{w}\left(u_{n}\right)\right\}_{n \in \mathbf{N}}$ is bounded and $\varphi_{w}^{\prime}\left(u_{n}\right) \rightarrow 0$ as $n \rightarrow+\infty$. We will prove that the sequence $\left\{u_{n}\right\}_{n \in \mathbf{N}}$ is bounded.

It follows from $\left(f_{3}\right),\left(f_{4}\right)$, and $\left(I_{2}\right)$ that

$$
\begin{aligned}
\mu \varphi_{w}\left(u_{n}\right)-\varphi_{w}^{\prime}\left(u_{n}\right) u_{n} & \\
=\left(\frac{\mu}{p}-1\right)\left\|u_{n}\right\|^{p}-\int_{0}^{T}( & \mu F\left(t, u_{n}, w^{\prime}\right) \\
& \left.-f\left(t, u_{n}, w^{\prime}\right) u_{n}\right) d t
\end{aligned}
$$




$$
\begin{aligned}
& +\sum_{j=1}^{l}\left[\mu \int_{0}^{u_{n}\left(t_{j}\right)} I_{j}(s) d s-I_{j}\left(u_{n}\left(t_{j}\right)\right) u_{n}\left(t_{j}\right)\right] \\
\geq & \left(\frac{\mu}{p}-1\right)\left\|u_{n}\right\|^{p}-\int_{\left|u_{n}\right| \geq x_{0}}\left(\mu F\left(t, u_{n}, w^{\prime}\right)\right. \\
& -\int_{\left|u_{n}\right| \leq x_{0}}\left(\mu F\left(t, u_{n}, w^{\prime}\right)-f\left(t, u_{n}, w^{\prime}\right) u_{n}\right) d t \\
\geq & \left.\left(\frac{\mu}{p}-1\right) \| u_{n}\right) d t
\end{aligned}
$$

Hence, $\left\{u_{n}\right\}$ is bounded in $W_{0}^{1, p}(0, T)$. The following proof of (PS)-condition is similar to that in (I) of Theorem 8.

(II) We verify assumption (ii) of Lemma 7.

Using $\left(I_{2}\right)$, we have

$$
\sum_{j=1}^{l} \int_{0}^{u\left(t_{j}\right)} I_{j}(t) d t \geq 0
$$

The proof is similar to that in (II) of Theorem 8 .

(III) We verify assumption (iii) of Lemma 7.

Take $v_{0} \in W_{0}^{1, p}(0, T)$ such that $\left\|v_{0}\right\|=1$. By $\left(I_{2}\right)$ and $\left(f_{5}\right)$, using Sobolev embedding theorem, we have

$$
\begin{aligned}
\varphi_{w}\left(s v_{0}\right)= & \frac{1}{p} s^{p}-\int_{0}^{T} F\left(t, s v_{0}(t), w^{\prime}(t)\right) \\
& +\sum_{j=1}^{l} \int_{0}^{s v_{0}\left(t_{j}\right)} I_{j}(t) d t \\
\leq & \frac{1}{p} s^{p}+l s\|u\|_{\infty}^{\theta}-C_{7}|s|^{\mu} \int_{0}^{T}\left|v_{0}(t)\right|^{\mu} d t-C_{8} T \\
\leq & \frac{1}{p} s^{p}+C_{9} s^{\theta}-C_{10}|s|^{\mu}-C_{8} T .
\end{aligned}
$$

Since $\mu>p \geq \theta,(63)$ implies that there exists $\xi_{2} \in R \backslash\{0\}$ such that $\|e\|>\rho$ and $\varphi_{w}(e)<0$ if we set $e=\xi_{2} v_{0}$. By Lemma 7, $\varphi_{w}$ possess a critical value $c^{\prime \prime} \geq \alpha>0$, given by

$$
c^{\prime \prime}=\inf _{g \in \Gamma} \max _{s \in[0,1]} \varphi_{w}(g(s)),
$$

where $\Gamma=\left\{g \in C\left([0,1], W_{0}^{1, p}(0, T)\right): g(0)=0, g(1)=e\right\}$. Obviously, $\varphi_{w}(0)=0$, so according to Lemma 7 , there exists $u_{w} \neq 0$ and $u_{w} \in X$, such that

$$
\varphi_{w}\left(u_{w}\right)=c^{\prime \prime}, \quad \varphi_{w}\left(u_{w}\right)=0 .
$$

(IV) We prove that $d_{5} \leq\left\|u_{w}\right\| \leq d_{6}$.

Like (IV) of Theorem 8 , we can obtain that there exist $d_{5}>0$ such that

$$
\left\|u_{w}\right\| \geq d_{5}
$$

It follows from $u_{w}$ satisfying (65) that

$$
\begin{aligned}
&\left(\frac{\mu}{p}-1\right)\left\|u_{w}\right\|^{p} \leq \mu \varphi_{w}\left(u_{w}\right)-\varphi_{w}^{\prime}\left(u_{w}\right) u_{w}+C_{11} \\
&=\mu \varphi_{w}\left(u_{w}\right)+C_{11} \\
&=\mu \inf _{g \in \Gamma} \max _{s \in[0,1]} \varphi_{w}(g(s))+C_{11} \\
& \leq \mu \max _{s \geq 0} \varphi_{w}\left(s v_{0}\right)+C_{11} \\
& \leq \mu\left(\frac{1}{p}|s|^{p}+\sum_{j=1}^{l} \int_{0}^{s v_{0}\left(t_{j}\right)} I_{j}(t) d t\right. \\
& \leq \mu\left(\frac{1}{p}|s|^{p}+|s|^{\theta} l\left\|v_{0}\right\|_{\infty}^{\theta}\right. \\
&\left.-a|s|^{\mu} \int_{0}^{T}\left|v_{0}\right|^{\mu} d t-b T\right)+C_{11} \\
&\left.\quad \int_{0}^{T}\left|v_{0}\right|^{\mu} d t+b T\right)+C_{11} .
\end{aligned}
$$

Let

$$
r(t)=\frac{1}{p}|t|^{p}+t^{\theta} l\left\|v_{0}\right\|_{\infty}^{\theta}-a t^{\mu} \int_{0}^{T}\left|v_{0}\right|^{\mu} d t, \quad t \geq 0 .
$$

Since $\mu>p \geq \theta$, then $r(t)$ can achieve its maximum at some $t$, which implies there exist $d_{6}>0$ such that

$$
\left\|u_{w}\right\| \leq d_{6}
$$

This completes the proof.

Lemma 11. Suppose that $\left(f_{1}\right)-\left(f_{3}\right)$ hold and $\left(f_{4}\right),\left(f_{5}\right)$, and $\left(I_{2}\right)$ hold only for positive $x$, then there exist positive constants $d_{7}$, and $d_{8}$ such that, for each $w \in W_{0}^{1, p}(0, T)$, problem (2) has a positive solution $u_{w}$ such that $d_{7} \leq\left\|u_{w}\right\| \leq d_{8}$.

Proof. The proof is similar to that of Lemma 9, so we omit it.

Remark 12. By the same method, we can discuss the negative solution of (2).

\section{The Solvability of (1)}

Theorem 13. Assume that $\left(f_{1}\right)-\left(f_{6}\right)$ and $\left(I_{1}\right)$ and $\left(I_{3}\right)$ hold; then problem (1) has one nontrivial solution provided

$$
k=\frac{L_{2} \lambda_{1}^{-1 / p} C_{1}^{-1-(1 / p)}}{C_{p}-L_{1} \lambda_{1}^{-1} C_{1}^{-1}-C_{2}^{p} \sum_{j=1}^{l} \alpha_{j}}
$$

satisfying $0<k<1$. 
Proof. We construct a sequence $\left\{u_{n}\right\} \in W_{0}^{1, p}(0, T)$ as solutions of the following problem:

$$
\begin{gathered}
-\left(\left|u_{n}^{\prime}(t)\right|^{p-2} u_{n}^{\prime}(t)\right)^{\prime}+g(t)\left|u_{n}(t)\right|^{p-2} u_{n}(t) \\
=f\left(t, u_{n}(t), u_{n-1}^{\prime}(t)\right), \quad t \neq t_{j}, \quad \text { a.e. } t \in[0, T], \\
\Delta u_{n}^{\prime}\left(t_{j}\right)=I_{j}\left(u_{n}\left(t_{j}\right)\right), \quad j=1,2, \ldots, l, \\
u_{n}(0)=u_{n}(T)=0
\end{gathered}
$$

obtained in Theorem 8, starting with an arbitrary $u_{0} \epsilon$ $W_{0}^{1, p}(0, T)$. It follows from the Sobolev embedding theorem that $\left\|u_{n}\right\|_{\infty} \leq \rho_{1}$. Using $\left(1.1_{n}\right)$ and $\left(1.1_{n+1}\right)$, we obtain

$$
\begin{aligned}
& \int_{0}^{T}\left|u_{n}^{\prime}(t)\right|^{p-2} u_{n}^{\prime}(t)\left(u_{n+1}^{\prime}-u_{n}^{\prime}\right) d t \\
& +\int_{0}^{T} g(t)\left|u_{n}(t)\right|^{p-2} u_{n}(t)\left(u_{n+1}-u_{n}\right) d t \\
& +\sum_{j=1}^{l} I_{j}\left(u_{n}\left(t_{j}\right)\right)\left(u_{n+1}\left(t_{j}\right)-u_{n}\left(t_{j}\right)\right) \\
& \quad=\int_{0}^{T} f\left(t, u_{n}, u_{n-1}^{\prime}\right)\left(u_{n+1}-u_{n}\right) d t, \\
& \int_{0}^{T}\left|u_{n+1}^{\prime}(t)\right|^{p-2} u_{n+1}^{\prime}(t)\left(u_{n+1}^{\prime}-u_{n}^{\prime}\right) d t \\
& +\int_{0}^{T} g(t)\left|u_{n+1}(t)\right|^{p-2} u_{n+1}(t)\left(u_{n+1}-u_{n}\right) d t \\
& +\sum_{j=1}^{l} I_{j}\left(u_{n+1}\left(t_{j}\right)\right)\left(u_{n+1}\left(t_{j}\right)-u_{n}\left(t_{j}\right)\right) \\
& =\int_{0}^{T} f\left(t, u_{n+1}, u_{n}^{\prime}\right)\left(u_{n+1}-u_{n}\right) d t .
\end{aligned}
$$

Hence,

$$
\begin{aligned}
& C_{p}\left(\int_{0}^{T}\left(\left|u_{n+1}^{\prime}-u_{n}^{\prime}\right|^{p}+g(t)\left|u_{n+1}-u_{n}\right|^{p}\right) d t\right) \\
& \leq \int_{0}^{T}\left[f\left(t, u_{n+1}, u_{n}^{\prime}\right)-f\left(t, u_{n}, u_{n-1}^{\prime}\right)\right]\left(u_{n+1}-u_{n}\right) d t \\
& \quad+\sum_{j=1}^{l}\left[I_{j}\left(u_{n}\left(t_{j}\right)\right)-I_{j}\left(u_{n+1}\left(t_{j}\right)\right)\right] \\
& \quad \times\left(u_{n+1}\left(t_{j}\right)-u_{n}\left(t_{j}\right)\right) \\
& \quad \int_{0}^{T}\left[f\left(t, u_{n+1}, u_{n}^{\prime}\right)-f\left(t, u_{n}, u_{n}^{\prime}\right)\right] \\
& \quad \times\left(u_{n+1}-u_{n}\right) d t \\
& \quad+\int_{0}^{T}\left[f\left(t, u_{n}, u_{n}^{\prime}\right)-f\left(t, u_{n}, u_{n-1}^{\prime}\right)\right]\left(u_{n+1}-u_{n}\right) d t
\end{aligned}
$$

$$
\begin{aligned}
& +\sum_{j=1}^{l}\left[I_{j}\left(u_{n}\left(t_{j}\right)\right)-I_{j}\left(u_{n+1}\left(t_{j}\right)\right)\right] \\
& \quad \times\left(u_{n+1}\left(t_{j}\right)-u_{n}\left(t_{j}\right)\right) \\
& \leq L_{1} \int_{0}^{T}\left|u_{n+1}-u_{n}\right|^{p} d t+L_{2} \int_{0}^{T}\left|u_{n}^{\prime}-u_{n-1}^{\prime}\right|^{p-1} \\
& \quad \times\left|u_{n+1}-u_{n}\right| d t \\
& +\sum_{j=1}^{l} \alpha_{j}\left|u_{n+1}\left(t_{j}\right)-u_{n}\left(t_{j}\right)\right|^{p} .
\end{aligned}
$$

Using (17) and (18) and by Hölder inequality, we have

$$
\begin{aligned}
& \left\|u_{n+1}-u_{n}\right\|^{p-1} \\
& \leq \frac{L_{2} \lambda_{1}^{-1 / p} C_{1}^{-1 / p}}{C_{p}-L_{1} \lambda_{1}^{-1} C_{1}^{-1}-C_{2}^{p} \sum_{j=1}^{l} \alpha_{j}}\left[\int_{0}^{T}\left|u_{n}^{\prime}-u_{n-1}^{\prime}\right|^{p} d t\right]^{(p-1) / p} \\
& =\frac{L_{2} \lambda_{1}^{-1 / p} C_{1}^{-1 / p}}{C_{p}-L_{1} \lambda_{1}^{-1} C_{1}^{-1}-C_{2}^{p} \sum_{j=1}^{l} \alpha_{j}}\left\|u_{n}-u_{n-1}\right\|_{W_{0}^{1, p}}^{p-1} \\
& \leq \frac{L_{2} \lambda_{1}^{-1 / p} C_{1}^{-1-(1 / p)}}{C_{p}-L_{1} \lambda_{1}^{-1} C_{1}^{-1}-C_{2}^{p} \sum_{j=1}^{l} \alpha_{j}}\left\|u_{n}-u_{n-1}\right\|^{p-1}
\end{aligned}
$$

that is,

$$
\left\|u_{n+1}-u_{n}\right\| \leq k^{1 /(p-1)}\left\|u_{n}-u_{n-1}\right\|
$$

Since $k$ is less than 1 , then it follows that $\left\{u_{n}\right\}$ strongly converges in $W_{0}^{1, p}(0, T)$, as it easily follows proving that $\left\{u_{n}\right\}$ is a Cauchy sequence in $W_{0}^{1, p}(0, T)$. By Theorem 8 , we know that $u \neq 0$. In this way we obtain a nontrivial solution of (1).

Example 14. Let $t_{1} \in(0, T)$ and $p=2$; consider the following nonlinear Dirichlet impulsive problem:

$$
\begin{gathered}
-u^{\prime \prime}(t)+(-1-t) u(t)=u^{3}(t)\left(1+\sin u^{\prime}(t)\right), \\
\text { a.e. } t \in[0, T], t \neq t_{1}, \\
\Delta u^{\prime}\left(t_{1}\right)=\sqrt[3]{u\left(t_{1}\right)}, \\
u(0)=u(T)=0 .
\end{gathered}
$$

Compared with (1), $f\left(t, u, u^{\prime}\right)=u^{3}\left(1+\sin u^{\prime}\right)$ and $I_{1}(u)=u^{1 / 3}$. We can take $\mu=3$ and $\theta=5 / 3$. Then by simple computation, it is easy to verify that all conditions of Theorem 13 are satisfied. Hence, by Theorem 13, problem (75) has one nontrivial solution. 
Theorem 15. Assume that $\left(f_{1}\right)-\left(f_{6}\right)$ and $\left(I_{2}\right)$ and $\left(I_{3}\right)$ hold; then problem (1) has one nontrivial solution provided

$$
k=\frac{L_{2} \lambda_{1}^{-1 / p} C_{1}^{-1-(1 / p)}}{C_{p}-L_{1} \lambda_{1}^{-1} C_{1}^{-1}-C_{2}^{p} \sum_{j=1}^{l} \alpha_{j}}
$$

satisfying $0<k<1$.

Proof. We construct a sequence $\left\{u_{n}\right\} \in W_{0}^{1, p}(0, T)$ as solutions of the problem $\left(1.1_{n}\right)$ obtained in Theorem 10 , starting with an arbitrary $u_{0} \in W_{0}^{1, p}(0, T)$. The rest of proof is similar to that of Theorem 13, so we omit it.

Example 16. Let $t_{1} \in(0, T)$ and $p=4$; consider the following nonlinear Dirichlet impulsive problem:

$$
\begin{gathered}
-\left(\left|u^{\prime}(t)\right|^{2} u^{\prime}(t)\right)^{\prime}-t^{2}|u(t)|^{2} u(t)=u^{7}(t)\left(2+\cos u^{\prime}(t)\right), \\
\text { a.e. } t \in[0, T], t \neq t_{1}, \\
\Delta u^{\prime}\left(t_{1}\right)=u^{2}\left(t_{1}\right), \\
u(0)=u(T)=0 .
\end{gathered}
$$

Compared with (1), $f\left(t, u, u^{\prime}\right)=u^{7}\left(2+\cos u^{\prime}\right)$ and $I_{1}(u)=$ $u^{2}$. We can take $\mu=6$ and $r_{1}=2$. Then by simple computation, it is easy to verify that all conditions of Theorem 15 are satisfied. Hence, by Theorem 15, problem (77) has one nontrivial solution.

Remark 17. In order to discuss the positive solutions of (1), we can argue as in Theorem 8 , by replacing $f$ by $\bar{f}$. By the same method, we can discuss the negative solutions of (1).

\section{Acknowledgments}

The authors are grateful to the referees for their useful suggestions. This work is partially supported by the National Natural Science Foundation of China (no. 71201013), the Humanities and Social Sciences Project of the Ministry of Education of China (no. 12YJC630118), the Innovation Platform Open Funds for Universities in Hunan Province (no. 13K059), and the Provincial Natural Science Foundation of Hunan (no. 11JJ3012).

\section{References}

[1] G. Zeng, F. Wang, and J. J. Nieto, "Complexity of a delayed predator-prey model with impulsive harvest and Holling type II functional response," Advances in Complex Systems, vol. 11, no. 1, pp. 77-97, 2008.

[2] R. K. George, A. K. Nandakumaran, and A. Arapostathis, "A note on controllability of impulsive systems," Journal of Mathematical Analysis and Applications, vol. 241, no. 2, pp. 276-283, 2000.

[3] G. Jiang, Q. Lu, and L. Qian, "Complex dynamics of a Holling type II prey-predator system with state feedback control," Chaos, Solitons \& Fractals, vol. 31, no. 2, pp. 448-461, 2007.
[4] G. Jiang, Q. Lu, and L. Qian, "Chaos and its control in an impulsive differential system," Chaos, Solitons \& Fractals, vol. 34, no. 4, pp. 1135-1147, 2007.

[5] J. Jiao, X. Yang, L. Chen, and S. Cai, "Effect of delayed response in growth on the dynamics of a chemostat model with impulsive input," Chaos, Solitons \& Fractals, vol. 42, no. 4, pp. 2280-2287, 2009.

[6] S. I. Nenov, "Impulsive controllability and optimization problems in population dynamics," Nonlinear Analysis. Theory, Methods \& Applications, vol. 36, no. 7, pp. 881-890, 1999.

[7] S. Tang and L. Chen, "Density-dependent birth rate, birth pulses and their population dynamic consequences," Journal of Mathematical Biology, vol. 44, no. 2, pp. 185-199, 2002.

[8] M. Choisy, J.-F. Guégan, and P. Rohani, "Dynamics of infectious diseases and pulse vaccination: teasing apart the embedded resonance effects," Physica D, vol. 223, no. 1, pp. 26-35, 2006.

[9] S. Gao, L. Chen, J. J. Nieto, and A. Torres, "Analysis of a delayed epidemic model with pulse vaccination and saturation incidence," Vaccine, vol. 24, pp. 6037-6045, 2006.

[10] G.-1. Cai and W.-G. Ge, "Positive solutions for second order impulsive differential equations with dependence on first order derivative," Journal of Mathematical Research and Exposition, vol. 26, no. 4, pp. 725-734, 2006.

[11] D. J. Guo and J. X. Sun, Functional Methods of Ordinary Differential Equation, Shandong Science Technology Press, Jinan, China, 1995.

[12] Y. P. Guo and W. G. Ge, "Positive solutions for three-point boundary value problems with dependence on the first order derivative," Journal of Mathematical Analysis and Applications, vol. 290, no. 1, pp. 291-301, 2004.

[13] J. H. Shen and W. B. Wang, "Impulsive boundary value problems with nonlinear boundary conditions," Nonlinear Analysis. Theory, Methods \& Applications, vol. 69, no. 11, pp. 4055-4062, 2008.

[14] Y. Zhao and H. Chen, "Multiplicity of solutions to two-point boundary value problems for second-order impulsive differential equations," Applied Mathematics and Computation, vol. 206, no. 2, pp. 925-931, 2008.

[15] D. De Figueiredo, M. Girardi, and M. Matzeu, "Semilinear elliptic equations with dependence on the gradient via mountainpass techniques," Differential and Integral Equations, vol. 17, no. 1-2, pp. 119-126, 2004.

[16] K. Teng and C. Zhang, "Existence of solution to boundary value problem for impulsive differential equations," Nonlinear Analysis. Real World Applications, vol. 11, no. 5, pp. 4431-4441, 2010.

[17] J. J. Nieto and D. O'Regan, "Variational approach to impulsive differential equations," Nonlinear Analysis. Real World Applications, vol. 10, no. 2, pp. 680-690, 2009.

[18] J. J. Nieto, "Variational formulation of a damped Dirichlet impulsive problem," Applied Mathematics Letters, vol. 23, no. 8, pp. 940-942, 2010.

[19] J. Xiao, J. J. Nieto, and Z. Luo, "Multiplicity of solutions for nonlinear second order impulsive differential equations with linear derivative dependence via variational methods," Communications in Nonlinear Science and Numerical Simulation, vol. 17, no. 1, pp. 426-432, 2012.

[20] Y. Tian and W. Ge, "Applications of variational methods to boundary-value problem for impulsive differential equations," Proceedings of the Edinburgh Mathematical Society, vol. 51, no. 2, pp. 509-527, 2008. 
[21] J. Sun and H. Chen, "Variational method to the impulsive equation with Neumann boundary conditions," Boundary Value Problems, vol. 2009, Article ID 316812, 17 pages, 2009.

[22] J. Sun, H. Chen, J. J. Nieto, and M. Otero-Novoa, “The multiplicity of solutions for perturbed second-order Hamiltonian systems with impulsive effects," Nonlinear Analysis. Theory, Methods \& Applications, vol. 72, no. 12, pp. 4575-4586, 2010.

[23] Z. Zhang and R. Yuan, "An application of variational methods to Dirichlet boundary value problem with impulses," Nonlinear Analysis. Real World Applications, vol. 11, no. 1, pp. 155-162, 2010.

[24] P. Chen and X. Tang, "Existence and multiplicity of solutions for second-order impulsive differential equations with Dirichlet problems," Applied Mathematics and Computation, vol. 218, no. 24, pp. 11775-11789, 2012.

[25] V. Lakshmikantham, D. D. Bainnov, and P. S. Simeonov, Theory of Impulsive Differential Equations, vol. 6, World Scientific Publishing Co. Inc., Singapore, 1989.

[26] P. Lindqvist, "On the equation $\operatorname{div}\left(|\nabla u|^{p-2} \nabla u\right)+\lambda|\nabla u|^{p-2} \nabla u=$ 0," Proceedings of the American Mathematical Society, vol. 109, no. 1, pp. 157-164, 1990. 


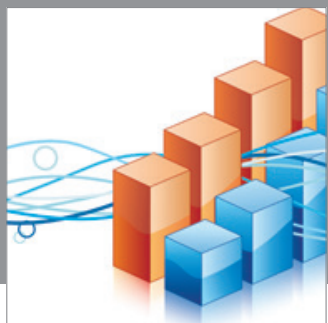

Advances in

Operations Research

mansans

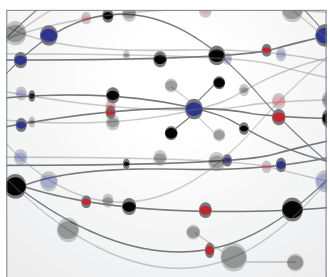

The Scientific World Journal
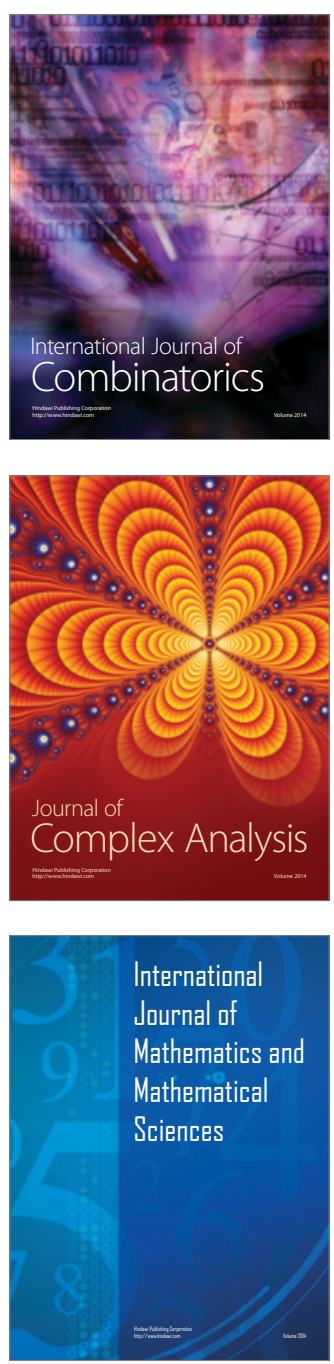
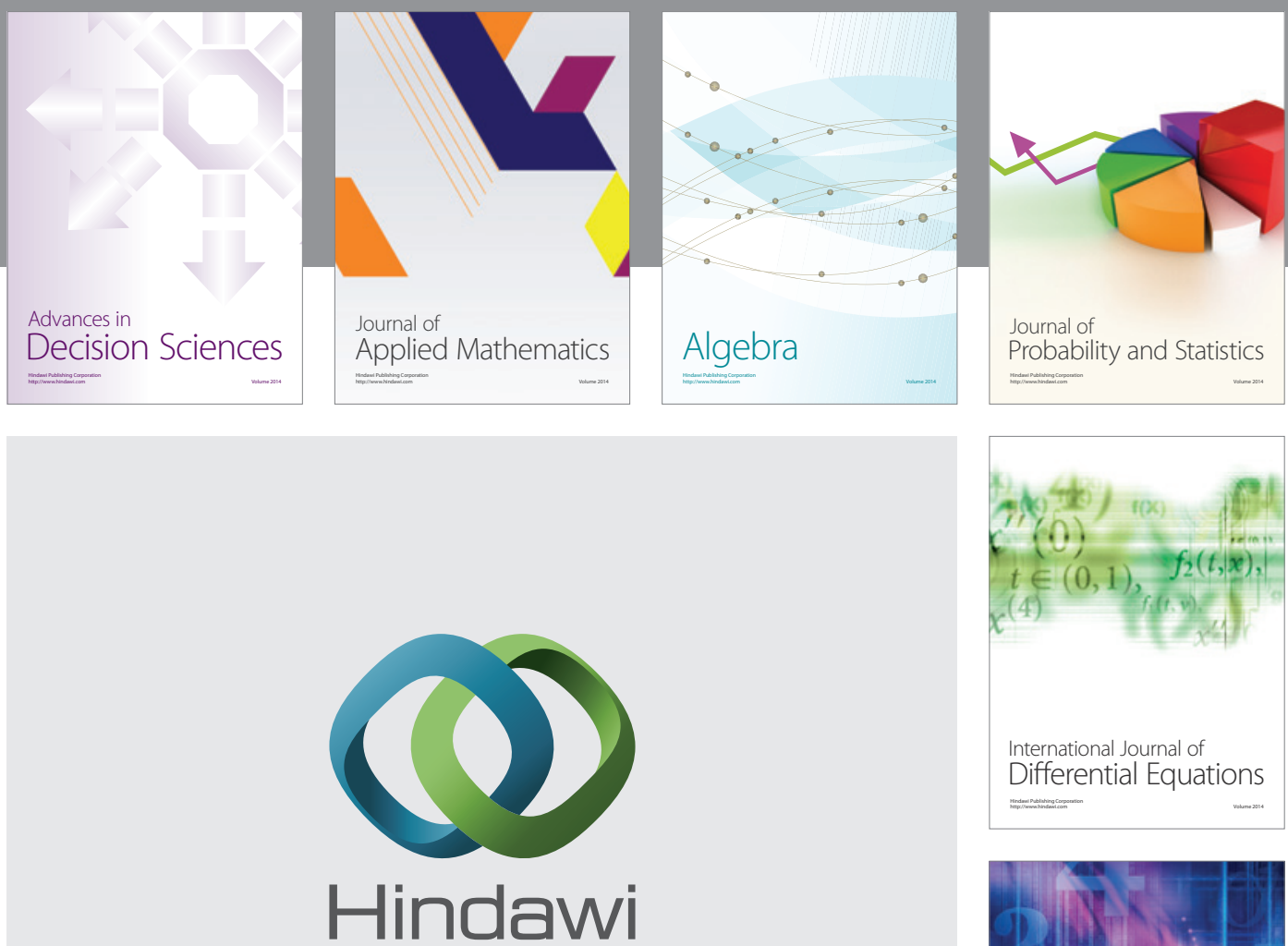

Submit your manuscripts at http://www.hindawi.com
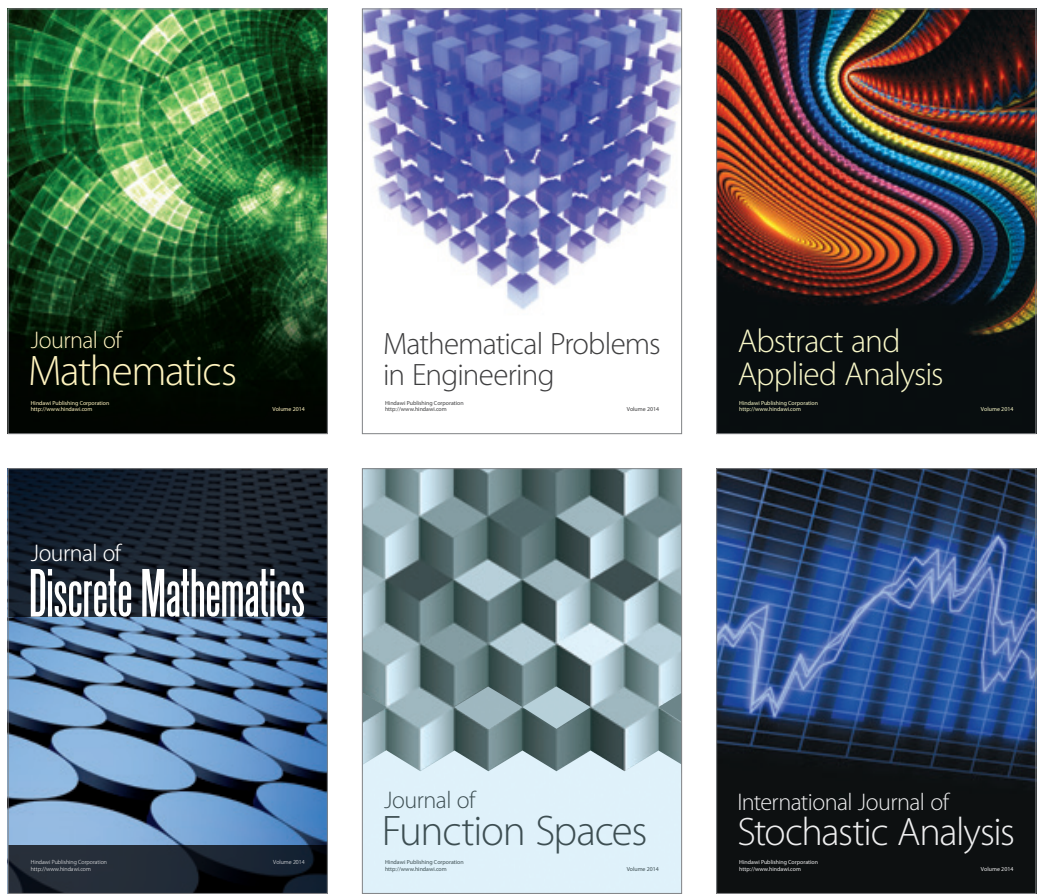

Journal of

Function Spaces

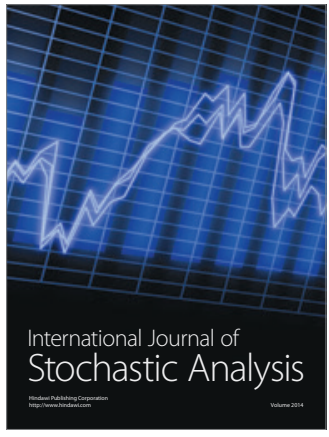

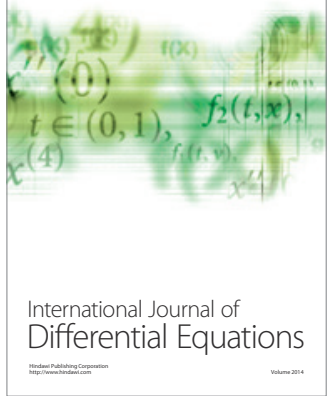
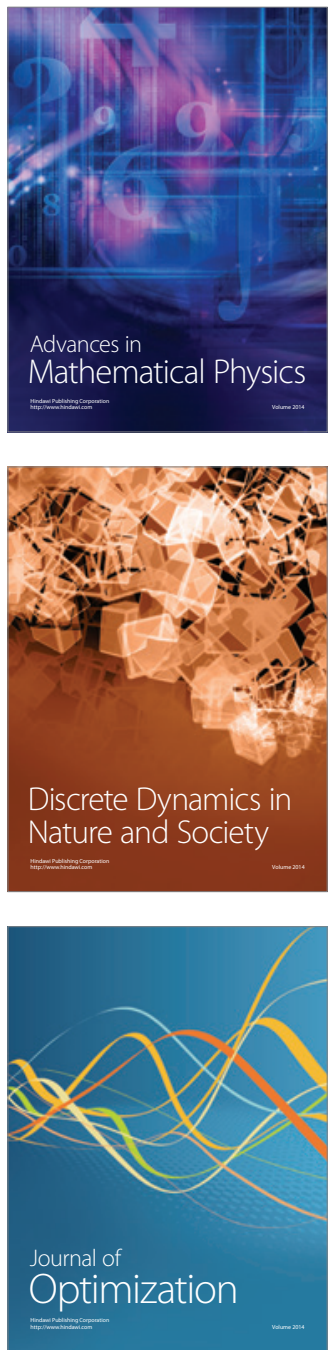